\title{
Analisis Pengaruh Kompetensi, Sarana Pendukung Teknologi Informasi Dan Kepuasan Kerja Sebagai Variabel Intervening Terhadap Kinerja SDM
}

\author{
Sugiyanto ; Djoko Santoso \\ sugivanto@yahoo.com; djoko_hw@usm.ac.id \\ Program Studi.Semarang.Indonsia
}

\begin{tabular}{l} 
Info Artikel \\
\hline Sejarah Artikel: \\
Diterima \\
Disetujui \\
Dipublikasikan \\
\hline Keywords: \\
Competence; information \\
technology as means of \\
support; job satisfaction, \\
performance of human \\
resources
\end{tabular}

\begin{abstract}
Abstrak
Penelitian ini bertujuan untuk mengetahui pengaruh kepemimpinan, pemberian insentif dan pelatihan kerja terhadap motivasi kerja dalam rangka meningkatkan produktivitas tenaga kerja di bagian produksi PT. Surya Rengo Containers - Semarang. Permasalahan dalam penelitian ini adalah apakah ada pengaruh antara kepemimpinan, pemberian insentif dan pelatihan kerja terhadap motivasi kerja dalam rangka meningkatkan produktivitas tenaga kerja.

Jenis penelitian yang digunakan dalam penelitian ini adalah jenis explanatory yaitu menjelaskan pengaruh antar variabel tertentu melalui pengujian hipotesis. Jenis data dalam penelitian ini menggunakan data primer yaitu data dari sumber utama dan diperoleh melalui kuisoner yang diperoleh dari karyawan di bagian produksi PT. Surya Rengo Containers - Semarang. Populasi dalam penelitian ini adalah semua karyawan di bagian produksi area corrugator PT. Surya Rengo Containers Semarang yang berjumlah 30 orang. Teknik pengambilan sampel dilakukan dengan metode sensus yaitu pengambilan sampel dimana setiap elemen penelitian mempunyai kemungkinan yang sama untuk dipilih. Sampling adalah suatu cara atau teknik yang dipergunakan untuk menentukan sampel penelitian (Supardi, 2005). Teknik penelitian menggunakan metode sensus yaitu seluruh popolasi dijadikan sampel yaitu sebanyak 30 orang.

Hasil analisis data menunjukkan bahwa kepemimpinan, pemberian insentif, pelatihan kerja serta motivasi kerja berpengaruh signifikan terhadap produktivitas tenaga kerja operator produksi pada PT. Surya Rengo Containers - Semarang.
\end{abstract}

\section{Analysis of the Effect of Competence, Supporting Facilities of Information Technology and Job Satisfaction as Intervening Variables on HR Performance}

\begin{abstract}
The study aimed to examine the effect of competencies and information technology as means of support to job satisfaction and performance of human resources, and also the effect of job satisfaction on the performance of human resources. The research problem is how to increase the performance of Customs officer through competence, information technology as means of support and job satisfaction.

This research was conducted at The Customs Office of
\end{abstract}


Semarang. Data were collected by distributing a questionnaire to present the questions covered by four variables with thirty four indicators. Processing data used Structural Equation Modeling (SEM) which was run by the software Analysis of Moment Structure (AMOS).

The results of data analysis concluded that the competence gave positive impact on job satisfaction, competence gave positive impact on the performance of human resources, information technology as means of support was not a positive effect on job satisfaction, information technology as means of support did not affect performance of human resources and job satisfaction gave positive effect on the performance of human resources. The empirical findings showed that competence affected job satisfaction, then job satisfaction will further affect performance of human resources.

\footnotetext{
${ }^{\bowtie}$ Alamat korespondensi :

Magister Manajemen.Universitas Semarang
}

E-mail: sugivanto@yahoo.com 


\section{PENDAHULUAN.}

Sumber Daya Manusia (SDM) sebagai pelaku utama organisasi mempunyai perbedaan dalam sikap dan pengetahuan. Perbedaan tersebut menyebabkan tiap individu mempunyai kinerja yang berbeda pula. Pengembangan kualitas SDM memegang peranan penting dalam kinerja pegawai.Kinerja merupakan wujud keberhasilan dalam tugas dan tanggung jawab yang diemban (Maier dalam Wijono, 2012). Apabila hal tersebut terpenuhi maka akan timbul perasaan tanggung jawab terhadap pekerjaan dan kesediaan untuk ikut berpartisipasi dalam mencapai tujuan organisasi melalui pelaksanaan tugas-tugas secara maksimal.

Kompetensi pegawai yang belum optimal dapat berdampak langsung pada kinerja pegawai, sehingga pegawai dituntut selalu proaktif untuk meningkatkan kemampuan dan keterampilannya.Wibowo (2012) menyampaikan bahwa kompetensi menunjukkan pengetahuan, keterampilan, dan sikap tertentu dari suatu profesi dalam ciri keahlian tertentu, yang menjadi ciri dari seorang profesional.Dengan demikian pegawai yang memiliki kompetensi tinggi akanmendapatkan kepuasan kerja dan kinerja SDM yang meningkat.

Salah satu faktor pendukung peningkatan pelayanan publik adalah sarana (Ridwan dan Sudrajat, 2014). Moenir (2014) mengemukakan sarana pendukung adalah segala jenisperalatan, perlengkapan kerja dan fasilitas yang berfungsi sebagai alat pendukung pelaksanaan pekerjaan dalam rangkakepentingan organisasi kerja.Dalam konteks sebagai sarana pendukung, teknologi informasi mempunyai peranan sangat penting dan dibutuhkan dalam mendukung kegiatan kantor modern. Teknologi informasi (hardware dan software) selain berfungsi untuk pemrosesan dan penyimpanan informasi, juga memiliki fungsi sebagai teknologi komunikasi untuk penyampaian dan penyebaran informasi.

Menurut Siagian (2013) kepuasan kerja merupakan suatu cara pandang seseorang baik yang positif maupun negatif tentang pekerjaannya.Kepuasan kerja adalah hal yang sangat personal, artinya yang dapat merasakan hanya yang bersangkutan saja dan sifatnya tidak selalu sama antara orang yang satu dengan orang yang lain. Kepuasan kerja dapat diamati secara langsung melalui ekspresi perasaan yang diungkapkan dalam pernyataan atau perilaku tertentu (Wijaya, 2012). Kepuasan kerja perlu diperhatikan oleh organisasi karena dengan mendapatkan kepuasan kerja, diharapkan kinerja SDM meningkat.

\section{Permasalahan}

Permasalahan penelitian yaitu bagaimana meningkatkan kinerja SDM pada KPPBC TMP A Semarangdirumuskan dengan pertanyaan penelitian sbb :

1. Adakah pengaruh kompetensi terhadap kinerja SDM?

2. Adakahpengaruh sarana pendukung TIterhadap kinerja SDM?

3. Adakah pengaruh kompetensi terhadap kepuasan kerja?

4. Adakah pengaruh sarana pendukung TI terhadap kepuasan kerja?

5. Adakah pengaruh kepuasan kerja terhadap kinerja SDM 


\section{TELAAH PUSTAKA}

\section{Hubungan Antara KompetensiTerhadap Kepuasan Kerja}

Kompetensi karyawansebagai karakteristik dari kemampuanseseorang dibutuhkan untuk mendapatkan hasilkerja yang baik sehingga menimbulkankepuasan kerja. Adanya pengaruh kompetensi terhadap kepuasan kerja dikemukakan oleh oleh Bogner dan Thomas dalam Sari (2013) bahwa "Kompetensi sebagai keahlian khusus yang dimiliki dan pengetahuan yang diarahkan untuk mencapai tingkat kepuasan yang tinggi".

Hasil penelitian Dhermawan, dkk. (2012) dan Jatnika (2017) menunjukkan kompetensi berpengaruh signifikan terhadap kepuasan kerja. Pegawai dengan kompetensi yang semakin baik, maka akan semakin baik pula kepuasan kerja yang dirasakan oleh pegawai, sehingga hipotesis yang diajukan dalam penelitian ini adalah:

H1 = Kompetensi berpengaruh positif terhadap Kepuasan Kerja.

\section{Hubungan Antara Sarana Pendukung Teknologi Informasi TerhadapKepuasan Kerja}

Menurut Rivai (2011) faktor yang dapat mempengaruhi kepuasan kerja karyawan yaitu faktor intrinsik dan ekstrinsik. Faktor ekstrinsik menyangkut halhal yang berasal dari luar diri karyawan, diantaranya yaitu fasilitas kerja. Fasilitas kerja adalah sarana pendukung dalam aktivitas perusahaan berbentuk fisik.

Meningkatnyaperkembangan lingkungan teknologi membawa konsekuensi terjadinya perubahan kondisi internal organisasi. Perubahan situasi yang terjadi menuntut adanya penyesuaian-penyesuaian antara lingkungan internal seperti motivasi, kreativitas dan perilaku dalam organisasi dengan perkembangan lingkungan teknologi (Widodo, 2008). Sarana teknologi informasi merupakan bagian dari lingkungan fisik kerja.

Kondisi lingkungan kerja yang sifatnya mendukung sangat berpengaruh bagi terciptanya kepuasan kerja (Siagian, 2012). Hasil penelitian Dahlius dan Ibrahim (2016) menyimpulkan fasilitas kerja berpengaruh signifikan terhadap kepuasan kerja karyawan. Penelitian Rosnidah (2012) hasilnya penggunaan teknologi informasi berpengaruh positif dan signifikan tehadap kepuasan kerja auditor.Hipotesis yang diajukan dalam penelitian ini adalah:

$\mathrm{H} 2$ = Sarana Pendukung Teknologi Informasi berpengaruh positif terhadap Kepuasan Kerja.

\section{Hubungan Antara KompetensiTerhadapKinerja SDM}

Seseorang yang memiliki kompetensi diharapkan mampu memberikan hasil yang sesuai standar organisasi baik dari segi kualitas, kuantitas maupun biaya. Seperti yang dikemukakan oleh Mangkunegara (2013), kinerja seseorang dipengaruhi oleh faktor: (1) kemampuan (ability) yang terdiri dari kemampuan reality (pengetahuan dan keterampilan), dan kemampuan potensi, dan (2) faktor motivasi (motivation) yang merupakan sikap (attitude) seseorang terhadap lingkungan organisasinya. Meskipun demikian, tidak selalu kompetensi akan menghasilkan kinerja sesuai standar organisasi karena tuntutan pekerjaan dan lingkungan organisasi juga faktor yang mempengaruhi output.

Menurut Wirawan (2012) kinerja mempunyai hubungan kausal dengan kompetensi. Kinerja merupakan fungsi dari kompetensi, sikap dan tindakan. 
Sementara Linjuan (2014) menyatakan bahwa kinerja tidak berdiri sendiri tapi juga berhubungan dengan kepuasan kerja dan kompensasi, dipengaruhi oleh ketrampilan, kemampuan dan sifat-sifat individu.

Robbins (2015) menegaskan bahwa pembeda antar individu adalah kemampuan seseorang untuk mengerjakan tugas dalam suatu pekerjaan. Seorang pegawai akan memiliki tingkat kinerja tinggi apabila terdapat kesesuaian antara pekerjaan dengan kemampuan. Hal ini sesuai dengan hasil penelitian Hadiyatno (2012) dan Pradiningrum, dkk (2013) bahwa variabel kompetensi mempunyai pengaruh signifikan terhadap kinerja pegawai. Penelitian Zarvedi, dkk (2016) hasilnya juga menyatakan kompetensi berpengaruh terhadap kinerja pegawai., sehingga hipotesis yang diajukan adalah:

H3 = Kompetensi berpengaruh positif terhadap Kinerja SDM.

\section{Hubungan Antara Sarana Pendukung Teknologi Informasi Terhadap Kinerja SDM}

Meningkatnyaperkembangan lingkungan membawa konsekuensi terjadinya perubahan kondisi internal organisasi. Perubahan situasi yang terjadi berdampak pada pemilihan kerja yang sesuai, yang menuntut adanya penyesuaianpenyesuaian antara lingkungan internal dengan perkembangan teknologi (Widodo, 2008). Cooper dan Makin dalam Poerwati (2003) berpendapat bahwa kinerja individu ditentukan oleh 3 hal utama, yaitu: harus memiliki alat yang tepat dalam pekerjaannya (sarana prasarana), harus memiliki kemampuan alami yang diperoleh melalui pendidikan dan pelatihan, harus memiliki motivasi atau dorongan untuk melaksanakan pekerjaannya.

Pemanfaatan teknologi informasi dalam organisasi diharapkan mampu meningkatkan kinerja pegawai. Anggota organisasi diharapkan mampu menggunakan teknologi untuk berkomunikasi dan mempercepat proses pertukaran atau arus informasi antar bagian sehingga hasil kinerja menjadi lebih bagus. Hal ini sesuai dengan penelitian dari Antasari dan Sukartha (2015) dan Geovanie, dkk (2016) bahwa pemanfaatan teknologi informasi berpengaruh positif terhadap kinerja individual pegawai, sehingga hipotesis yang diajukan dalam penelitian ini: H4 = Sarana Pendukung Teknologi Informasi berpengaruh positif terhadap Kinerja SDM.

\section{Hubungan Antara Kepuasan Kerja TerhadapKinerja SDM}

Menurut Robbins (2015), seseorang dengan tingkat kepuasan kerja yang tinggi menunjukkan sikap positif terhadap kerja, sedangkan seseorang yang tidak puas dengan pekerjaannya akan menunjukkan sikap yang negatif terhadap pekerjannya. Individu dengan kepuasan kerja diharapkan akan mengeluarkan seluruh kemampuan dan energi yang dimiliki untuk menyelesaikan pekerjaan, sehingga dapat menghasilkan kinerja yang optimal. Kepuasan kerja sering dijadikan ukuran tingkat kematangan dalam kehidupan organisasi modern.

Linjuan (2014) menyatakan bahwa kinerja tidak berdiri sendiri tapi berhubungan juga dengan kepuasan kerja. Penelitian Astuti (2010) menunjukkan bahwa adanya peningkatan kepuasan kerja akan memberikan pengaruh pada kinerja karyawan. Penelitian Dhermawan (2012) juga menyatakan terdapat pengaruh yang positif dan signifikan antara variabel kepuasan kerja terhadap variabel kinerja,sehingga hipotesis yang diajukan dalam penelitian ini adalah: 


\section{H5 = Kepuasan Kerja berpengaruh positif terhadap Kinerja SDM.}

\section{METODE}

Populasi dalam penelitian ini adalah seluruh pegawai KPPBC TMP A Semarang berjumlah 201 orang. Standar minimal sampel ideal dengan analisis SEM menurut Ferdinand (2014) yang sesuai adalah 100-200. Sedangkan teknik sampling dilakukan dengan sensus.

Untuk dapat menjawab pertanyaan penelitian danmenilai model yang disusun, teknik analisis yangdigunakan adalah Structural Equation Modeling(SEM) dengan menggunakan paket program AMOS(Analysis of Moment Structure) versi 2.2 dan SPSS(Statistical Program for Social Sciences) versi 2.2.Penggunaan SEM memungkinkan peneliti untukmenguji hubungan antara variabel yang kompleksuntuk memperoleh gambaran menyeluruh mengenaikeseluruhan model. SEM dapat menguji secarabersama-sama (Ghozali,2014).

\section{Variabel Dan Indikator Penelitian}

Tabel 3.1.

Variabel dan Indikator

\begin{tabular}{|c|c|c|c|}
\hline No & Variabel & Indikator & Sumber \\
\hline 1. & Kompetensi & $\begin{array}{ll}\text { 1. } & \text { Inisiatif }(x 1) \\
\text { 2. } & \text { Berpikir analitik }(x 2) \\
\text { 3. } & \text { Keahlian praktikal }(x 3) \\
\text { 4. } & \text { Pengendalian diri }(x 4) \\
\text { 5. } & \text { Percaya diri (x5) } \\
\text { 6. } & \text { Kemampuan beradaptasi }(x 6) \\
\text { 7. } & \text { Pengaruh dan dampak (x7) } \\
\text { 8. } & \text { Membangun hubungan kerja (x8) } \\
\text { 9. } & \text { Kerja tim (x9) }\end{array}$ & $\begin{array}{l}\text { Spencer dan } \\
\text { Spencer } \\
\text { dalam } \\
\text { Sudarmanto } \\
\text { (2009) }\end{array}$ \\
\hline 2. & $\begin{array}{c}\text { Sarana } \\
\text { Pendukung } \\
\text { Teknologi } \\
\text { Informasi }\end{array}$ & $\begin{array}{l}\text { 1. Software/aplikasi mudah digunakan (x10) } \\
\text { 2. Hardwaresudah lengkap (x11) } \\
\text { 3. Jaringan komputer lokal (intranet) baik (x12) } \\
\text { 4. Jaringan internet terpasang baik (x13) } \\
\text { 5. pengiriman data/informasi relatif cepat (x14) } \\
\text { 6. Data/informasi yang dikirimkan diterima utuh (x15) } \\
\text { 7. Data/informasi dapat terjamin kerahasiaannya (x16) }\end{array}$ & $\begin{array}{l}\text { Kadir } \\
\text { danTriwahyun } \\
\text { i dalam } \\
\text { Pariyatin } \\
(2015)\end{array}$ \\
\hline 3. & $\begin{array}{l}\text { Kepuasan } \\
\text { Kerja }\end{array}$ & $\begin{array}{l}\text { 1. Gaji yang lebih baik (x17) } \\
\text { 2. Tunjangan lebih baik (x18) } \\
\text { 3. Dukungan rekan kerja (x19) } \\
\text { 4. Senang bekerja dengan rekan (x20) } \\
\text { 5. Dukungan atasan (x21) } \\
\text { 6. Motivasi kerja atasan (x22) } \\
\text { 7. Pekerjaan sangat menarik (x23) } \\
\text { 8. } \text { Bertanggung jawab (x24) }\end{array}$ & $\begin{array}{l}\text { Celluci dan De } \\
\text { Vries dalam } \\
\text { Mariam } \\
(2009)\end{array}$ \\
\hline 4. & Kinerja SDM & $\begin{array}{ll}\text { 1. } & \text { Bekerja ekstra }(\mathrm{x} 25) \\
\text { 2. } & \text { Bekerja lebih keras }(\mathrm{x} 26) \\
\text { 3. } & \text { Orientasi pada pengguna jasa }(\times 27) \\
\text { 4. } & \text { Inisiatif bekerja mandiri (x28) } \\
\text { 5. } & \text { Tepat waktu (x29) } \\
\text { 6. } & \text { Alokasi waktu (x30) }\end{array}$ & $\begin{array}{l}\text { Bono dan } \\
\text { Judge dalam } \\
\text { Mariam } \\
(2009)\end{array}$ \\
\hline
\end{tabular}




\begin{tabular}{|l|l|l|}
\hline 7. & Kualitas kerja (x31) \\
8. & Menyelesaikan pekerjaan dengan baik (x32) \\
9. & Bekerja sama dengan rekan (x33) \\
10. & Pahami kebutuhan pengguna jasa (x34)
\end{tabular} \mid

Sumber: Disarikandariberbagaipenelitian,2017

\section{HASIL DAN PEMBAHASAN}

Dalam pengumpulan data, peneliti menggunakan metode sensus dengan mendistribusikan kuesioner ke seluruh pegawai sejumlah 201. Sampai batas waktu yang ditentukan, kuesioner yang kembali dan mendapat tanggapan sejumlah 158, sedangkan 43kuesioner tidak kembali karena responden tidak memberi tanggapan.

\section{Analisis Structural Equation Modelling (SEM)}

Gambar 4.2

Full Model Struktural

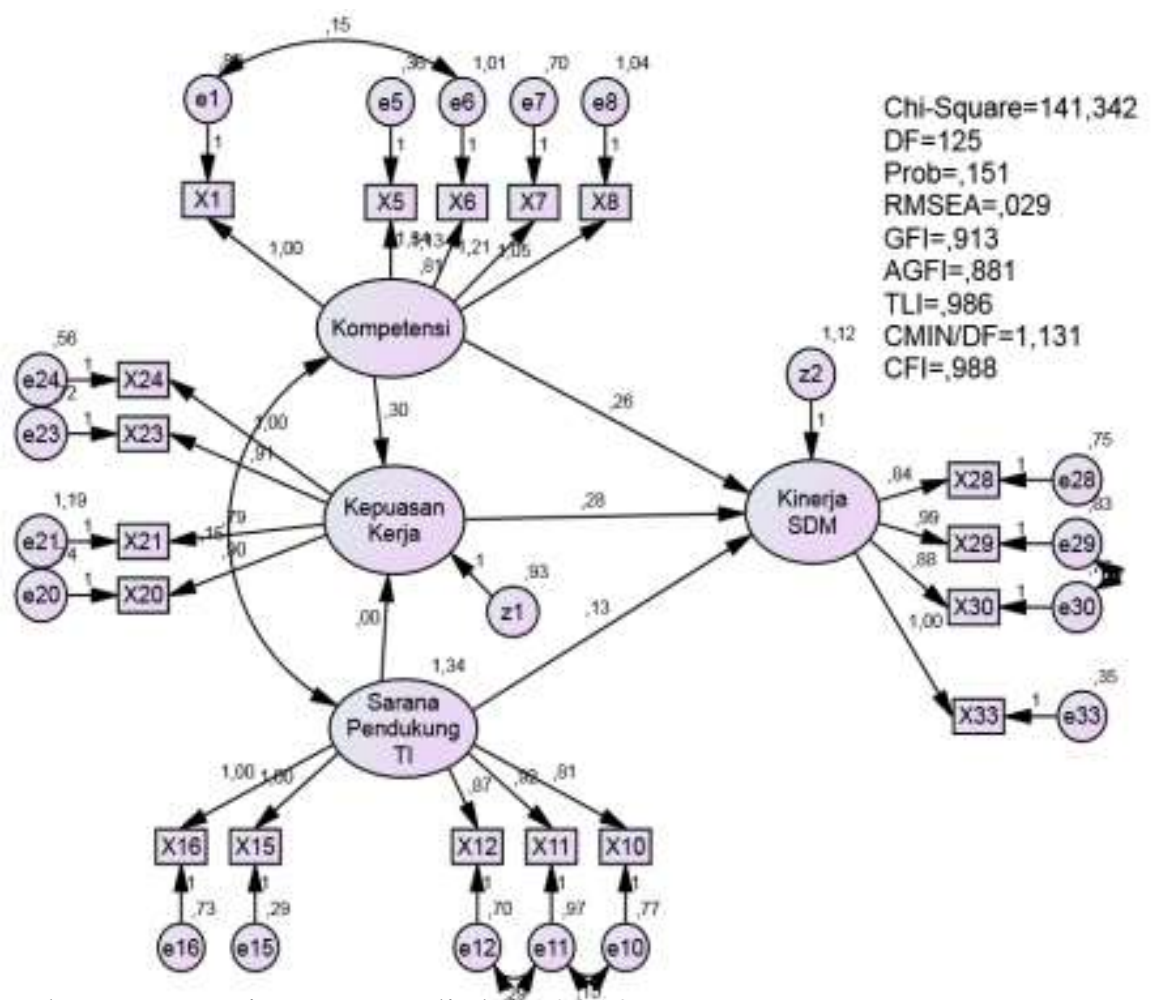

Sumber: Data Primer yang diolah, 2018

\section{Uji Kesesuaian Model - Goodness of Fit Test}

Uji ini dilakukan untuk tujuan diketahuinya seberapa baik tingkat Goodness of Fit dari model penelitian. Penelitian ini harus memenuhi beberapa kriteria yang dipersyaratkan dalam SEM. Hasil pengolahan data diharapkan memenuhi batas statistik yang telah ditentukan. Hasil uji kesesuaian model tampak sebagai berikut. 
Tabel 4.7

Goodness of Fit Indices untuk Full Model

\begin{tabular}{|c|c|c|c|}
\hline Goodness of Fit & Cut off Value & Hasil & Keterangan \\
\hline Chi-Square & Diharap kecil & $\mathbf{1 4 1 , 3 4 2}$ & Baik \\
\hline Probability & $\geq 0,05$ & $\mathbf{0 , 1 5 1}$ & Baik \\
\hline RMSEA & $\leq \mathbf{0 , 0 8}$ & $\mathbf{0 , 0 2 9}$ & Baik \\
\hline GFI & $\geq 0,90$ & $\mathbf{0 , 9 1 3}$ & Baik \\
\hline AGFI & $\geq 0,90$ & $\mathbf{0 , 8 8 1}$ & Marjinal \\
\hline TLI & $\geq 0,90$ & $\mathbf{0 , 9 8 6}$ & Baik \\
\hline CMIN/DF & $\leq 2,00$ & 1,131 & Baik \\
\hline CFI & $\geq 0,95$ & $\mathbf{0 , 9 8 8}$ & Baik \\
\hline
\end{tabular}

Sumber: Data Primer yang diolah, 2018

Dari Gambar 4.2 dan Tabel 4.7 di atas dapat ditarik kesimpulan bahwa:

- Tingkat signifikansi uji hipotesis perbedaan adalah $\chi^{2}$ - Chi Square sebesar 141,342 dengan $\mathrm{p}=0,151$, menunjukkan bahwa hipotesis nol yang menyatakan tidak terdapat perbedaan antara matriks kovarianssampel dan matriks kovarians populasi yang diestimasi tidak dapat ditolak, berarti hipotesa nol diterima.

- Indeks Chi-square, probabilitas, CMIN/DF, GFI, AGFI, TLI, CFI dan RMSEA memberikan konfirmasi yang cukup bahwa model ini dapat diterima karena berada padarentang nilai yang diharapkan, secara umum tingkat kelayakan (Goodness of Fit) baik.

\section{Uji Kausalitas : Regression Weight}

Tabel 4.8

Hasil pengujian Structural Equation Model

\begin{tabular}{|lrl|r|r|l|}
\hline & & & C.R. & P & Keterangan \\
\hline Kompetensi & $\rightarrow$ & Kepuasan Kerja & 2,770 &, 006 & Signifikan \\
Sarana Pendukung TI $\rightarrow$ & Kepuasan Kerja &,- 043 &, 966 & Tidak signifikan \\
Kompetensi & $\rightarrow$ & Kinerja SDM & 2,199 &, 028 & Signifikan \\
Sarana Pendukung TI $\rightarrow$ & Kinerja SDM & 1,472 &, 141 & Tidak signifikan \\
Kepuasan Kerja & $\rightarrow$ & Kinerja SDM & 2,609 &, 009 & Signifikan \\
\hline
\end{tabular}

Sumber: Data Primer yang diolah, 2018

Dari Tabel 4.8 dapat disimpulkan bahwa dengan nilai C.R. >1,96 mengindikasikan diterimanya 3 (tiga) model hipotesis dalam penelitian ini, yakni H1, H3 dan H5. Sedangkan 2 (dua) hipotesis yakni H2 dan H4 memiliki C.R.< 1,96, sehingga hipotesis tidak dapat diterima.

\section{Evaluasi atas Asumsi-Asumsi SEM}


1) Evaluasi Univariate Outliers. Deteksi adanya univariate outliers dengan menentukan ambang batas dengan cara mengkonversi nilai data penelitian ke dalam standard score(z-score) yang mempunyai rata-rata nol dengan standard deviasi sebesar 1,00 (Hair, dkk dalam Andini, 2006). Observasi data yang memiliki nilai z-score $>3,0$ akan dikategorikan sebagai outliers. Hasil pengujian univariate outliers menunjukkan tidak adanya univariate outliers.

Tabel 4.9

Descriptive Statistics

\begin{tabular}{|c|c|c|c|c|c|}
\hline & $\mathrm{N}$ & Minimum & Maximum & Mean & Std. Deviation \\
\hline Zscore $(x 1)$ & 158 & $-1,80155$ & 1,25914 & .0000000 & 1,00000000 \\
\hline Zscore (x2) & 158 & $-1,70441$ & 1,41787 &, 0000000 & 1,00000000 \\
\hline Zscore (x3) & 158 & $-1,56880$ & 1,37328 &, 0000000 & 1,00000000 \\
\hline Zscore $(x 4)$ & 158 & $-1,78517$ & 1,33148 & ,0000000 & 1,00000000 \\
\hline Zscore $(x 5)$ & 158 & $-1,57002$ & 1,30608 & ,0000000 & 1,00000000 \\
\hline Zscore(x6) & 158 & $-1,44462$ & 1,34743 &, 0000000 & 1,00000000 \\
\hline Zscore $(x 7)$ & 158 & $-1,58287$ & 1,32519 & .0000000 & 1,00000000 \\
\hline Zscore $(x 8)$ & 158 & $-1,68604$ & 1,17841 & ,0000000 & 1,00000000 \\
\hline Zscore(x9) & 158 & $-1,80640$ & 1,31285 & .0000000 & 1,00000000 \\
\hline Zscore $(x 10)$ & 158 & $-1,73817$ & 1,36500 & ,0000000 & 1,00000000 \\
\hline Zscore (x11) & 158 & $-1,42953$ & 1,32493 & .0000000 & 1,00000000 \\
\hline Zscore(x12) & 158 & $-1,81732$ & 1,23732 &, 0000000 & 1,00000000 \\
\hline Zscore (x13) & 158 & $-1,60618$ & 1,43306 & ,0000000 & 1,00000000 \\
\hline Zscore (x14) & 158 & $-1,90367$ & 1,33053 & ,0000000 & 1,00000000 \\
\hline Zscore (x15) & 158 & $-1,82133$ & 1,28970 & ,0000000 & 1,00000000 \\
\hline Zscore (x16) & 158 & $-1,67672$ & 1,09733 & ,0000000 & 1,00000000 \\
\hline Zscore (x17) & 158 & $-1,43795$ & 1,55148 & ,0000000 & 1,00000000 \\
\hline Zscore (x18) & 158 & $-1,35763$ & 1,25829 & ,0000000 & 1,00000000 \\
\hline Zscore (x19) & 158 & $-1,47289$ & 1,64038 & ,0000000 & 1,00000000 \\
\hline Zscore $(\times 20)$ & 158 & $-1,73020$ & 1,46713 & ,0000000 & 1,00000000 \\
\hline Zscore $(x 21)$ & 158 & $-1,84279$ & 1,11315 & ,0000000 & 1,00000000 \\
\hline Zscore (x22) & 158 & $-1,48426$ & 1,29928 & ,0000000 & 1,00000000 \\
\hline Zscore (x23) & 158 & $-1,82809$ & 1,36349 & ,0000000 & 1,00000000 \\
\hline Zscore (x24) & 158 & $-1,77025$ & 1,41721 & ,0000000 & 1,00000000 \\
\hline Zscore (x25) & 158 & $-1,56567$ & 1,28593 & ,0000000 & 1,00000000 \\
\hline Zscore $(x 26)$ & 158 & $-1,41719$ & 1,35576 & ,0000000 & 1,00000000 \\
\hline Zscore $(x 27)$ & 158 & $-1,41081$ & 1,59132 & ,0000000 & 1,00000000 \\
\hline Zscore $(x 28)$ & 158 & $-1,70607$ & 1,37461 & ,0000000 & 1,00000000 \\
\hline Zscore (x29) & 158 & $-1,45819$ & 1,30102 & ,0000000 & 1,00000000 \\
\hline Zscore $(x 30)$ & 158 & $-1,81464$ & 1,22741 &, 0000000 & 1,00000000 \\
\hline Zscore $(x 31)$ & 158 & $-1,59634$ & 1,46089 & ,0000000 & 1,00000000 \\
\hline Zscore $(x 32)$ & 158 & $-1,89978$ & 1,31915 &, 0000000 & 1,00000000 \\
\hline Zscore $(x 33)$ & 158 & $-1,81057$ & 1,29046 & .0000000 & 1,00000000 \\
\hline Zscore(x34) & 158 & $-1,66375$ & 1,10333 &, 0000000 & 1,00000000 \\
\hline Valid N (listwise) & 158 & & & & \\
\hline
\end{tabular}

Sumber: Data Primer yang diolah, 2018

2) Evaluasi Normalitas Data

Uji normalitas dilakukan dengan menggunakan kriteria C.R. $\pm 2,58$ pada

tingkat signifikansi 0,01 (1\%). Hasil uji normalitas data dari penelitian ini dapat

dilihat pada Tabel 4.10 berikut ini:

Tabel 4.10 
Assessment of normality

\begin{tabular}{|l|rrrrrr|}
\hline Variable & min & $\max$ & skew & c.r. & kurtosis & c.r. \\
\hline X10 & 1,000 & 5,000 &,- 455 & $-2,333$ &,- 962 & $-2,469$ \\
X16 & 1,000 & 5,000 &,- 359 & $-1,844$ & $-1,308$ & $-3,356$ \\
X15 & 1,000 & 5,000 &,- 314 & $-1,611$ & $-1,066$ & $-2,734$ \\
X12 & 1,000 & 5,000 &,- 351 & $-1,801$ & $-1,162$ & $-2,981$ \\
X11 & 1,000 & 5,000 &,- 107 &,- 551 & $-1,408$ & $-3,614$ \\
X8 & 1,000 & 5,000 &,- 339 & $-1,741$ & $-1,204$ & $-3,088$ \\
X7 & 1,000 & 5,000 &,- 130 &,- 665 & $-1,225$ & $-3,143$ \\
X6 & 1,000 & 5,000 &,- 109 &,- 562 & $-1,315$ & $-3,373$ \\
X5 & 1,000 & 5,000 &,- 306 & $-1,572$ & $-1,125$ & $-2,887$ \\
X1 & 1,000 & 5,000 &,- 367 & $-1,883$ &,- 994 & $-2,550$ \\
X33 & 1,000 & 5,000 &,- 303 & $-1,556$ & $-1,089$ & $-2,794$ \\
X24 & 1,000 & 5,000 &,- 385 & $-1,975$ &,- 893 & $-2,291$ \\
X23 & 1,000 & 5,000 &,- 446 & $-2,287$ &,- 741 & $-1,902$ \\
X21 & 1,000 & 5,000 &,- 513 & $-2,630$ & $-1,072$ & $-2,750$ \\
X20 & 1,000 & 5,000 &,- 294 & $-1,507$ &,- 945 & $-2,425$ \\
X30 & 1,000 & 5,000 &,- 350 & $-1,796$ & $-1,171$ & $-3,005$ \\
X29 & 1,000 & 5,000 &,- 149 &,- 764 & $-1,394$ & $-3,577$ \\
X28 & 1,000 & 5,000 &,- 422 & $-2,164$ & $-1,001$ & $-2,568$ \\
Multivariate & & & & & 7,728 & $\mathbf{1 , 8 1 0}$ \\
\hline
\end{tabular}

Sumber: Data Primer yang diolah, 2018

Dari tabel di atas, uji normalitas data dengan normalitas Univariate dan Multivariate, yaitu menganalisis tingkat normalitas data yang digunakan dalam penelitian ini. Univariate melihat nilai CR pada Skewness diharapkan disekitar \pm 2.58 . Bila ada nilai diluar angka tersebut bisa ditoleransi apabila nilai Multivariatenya masih disekitar \pm 2.58 , karena itu dapat dikatakan bahwa tidak terdapat bukti bahwa distribusi data ini tidak normal.

3) Evaluasi Outlier Multivariate.

Outlier pada tingkat multivariate dapat dilihat dari mahalanobis distance. dengan menggunakan program AMOS 2.2. Dari hasil pengolahan data diketahui bahwa jarak mahalanobis minimal adalah 15,889 dan maksimal adalah 32,376. Berdasarkan nilai Chi-square pada derajat bebas 34 (jumlah variabel) pada tingkat signifikansi 0,001 atau $\chi^{2}(34,0.001)=56,061$, menunjukkan bahwa tidak terdapat outlier multivariate.

4) Evaluasi atas Multikolinearitas dan Singularitas

Indikasi adanya multikolinearitas dan singularitas dapat diketahui melalui nilai determinan matriks kovarian yang benar-benar kecil, atau mendekati nol. Dari hasil pengolahan diketahui nilai determinan matriks kovarians sampel sebesar 1,544. Melihat nilai determinan matriks kovarians sampel yang jauh dari nilai nol, maka dapat disimpulkan bahwa data penelitian ini terbebas dari multikolinearitas dan singularitas. 


\section{Pengujian Hipotesis}

1) Pengujian Hipotesis Pertama (H1), kompetensi berpengaruh positif terhadap kepuasan kerja.Parameter estimasi untuk pengujian kompetensi terhadap kepuasan kerja menunjukkan nilai CR sebesar 2,730 dan dengan probabilitas sebesar 0,006. Kedua nilai tersebut memenuhi syarat untuk penerimaan H1 yaitu nilai CR yang $>1,96$ dan probabilitas $<0,05$. Dengan demikian hipotesis bahwa kompetensi akan berpengaruh positif terhadap kepuasan kerjaditerima.

2) Pengujian Hipotesis Kedua (H2),sarana pendukung teknologi informasi berpengaruh positif terhadap kepuasan kerja.Parameter estimasi untuk pengujian sarana pendukung teknologi informasi terhadap kepuasan kerja menunjukkan nilai CR sebesar -0,043 dan dengan probabilitas sebesar 0,966. Kedua nilai tersebut tidak memenuhi syarat untuk penerimaan $\mathrm{H} 2$ yaitu nilai CR yang harus $>1,96$ dan probabilitas harus $<0,05$. Dengan demikian hipotesis bahwa sarana pendukung teknologi informasi berpengaruh positif terhadap kepuasan kerjaditolak.

3) Pengujian Hipotesis Ketiga(H3), kompetensi berpengaruh positif terhadap kinerja SDM.Parameter estimasi untuk pengujian kompetensi terhadap kinerja SDM menunjukkan nilai CR sebesar 2,199, memenuhi syarat untuk nilai CR > 1,96, sedangkan probabilitassebesar 0,028, artinya jugamemenuhi syarat probabilitas $<0,05$. Dengan demikian hipotesis bahwakompetensi berpengaruh positif terhadap kinerja SDMditerima.

4) Pengujian Hipotesis Keempat(H4), sarana pendukung teknologi informasi berpengaruhpositif terhadap kinerja SDM. Parameter estimasi untuk pengujian sarana pendukung teknologi informasi terhadap kinerja SDM menunjukkan nilai CR sebesar 1,472 yang tidak memenuhi syarat nilai CR yang > 1,96, sedangkan probabilitas sebesar 0,141 juga tidak memenuhi syarat probabilitas $<0,05$. Dengan demikian hipotesis bahwa sarana pendukung teknologi informasi berpengaruh positif terhadap kinerja SDMditolak.

5) Pengujian Hipotesis Kelima(H5), kepuasan kerja berpengaruhpositif terhadap kinerja SDM. Parameter estimasi untuk pengujian kepuasan kerja terhadap kinerja SDM menunjukkan nilai CR sebesar 2,701 dan dengan probabilitas 
sebesar 0,007. Kedua nilai tersebut memenuhi syarat untuk penerimaan hipotesis yaitu nilai CR yang $>1,96$ dan probabilitas $<0,05$. Dengan demikian hipotesis bahwa kepuasan kerja berpengaruh positif terhadap kinerja SDMditerima.

\section{Analisis Pengaruh}

Analisis pengaruh dilakukan untuk menganalisis kekuatan pengaruh antar konstruk baik pengaruh yang langsung, tidak langsung dan pengaruh totalnya. Besar pengaruh masing-masing variabel secara langsung, tidak langsung, dan total tampak pada tabel berikut ini.

Tabel 4.11

Estimasi Pengaruh Langsung

Direct Effects (Group number 1 - Default model)

\begin{tabular}{|l|rrrr|}
\hline & $\begin{array}{l}\text { Sarana } \\
\text { Pendukung_TI }\end{array}$ & Kompetensi & $\begin{array}{l}\text { Kepuasan } \\
\text { Kerja }\end{array}$ & $\begin{array}{l}\text { Kinerja } \\
\text { SDM }\end{array}$ \\
\hline Kepuasan_Keria &,- 003 &, 298 &, 000 &, 000 \\
Kinerja_SDM &, 125 &, 258 &, 285 &, 000 \\
\hline
\end{tabular}

Sumber: Data Primer yang diolah, 2018

Tabel 4.12

Estimasi Pengaruh Tidak Langsung

Indirect Effects (Group number 1 - Default model)

\begin{tabular}{|l|rrrr|}
\hline & $\begin{array}{l}\text { Sarana } \\
\text { Pendukung_TI }\end{array}$ & Kompetensi & $\begin{array}{l}\text { Kepuasan } \\
\text { Kerja }\end{array}$ & $\begin{array}{l}\text { Kinerja } \\
\text { SDM }\end{array}$ \\
\hline Kepuasan_Keria &, 000 &, 000 &, 000 &, 000 \\
Kineria_SDM &,- 001 &, 085 &, 000 &, 000 \\
\hline
\end{tabular}

Sumber: Data Primer yang diolah, 2018

Tabel 4.13

Estimasi Pengaruh Total

Total Effects (Group number 1 - Default model)

\begin{tabular}{|c|c|c|c|c|}
\hline & $\begin{array}{l}\text { Sarana } \\
\text { Pendukung_TI }\end{array}$ & Kompetensi & $\begin{array}{l}\text { Kepuasan } \\
\text { Kerja }\end{array}$ & $\begin{array}{l}\text { Kinerja } \\
\text { SDM }\end{array}$ \\
\hline Kepuasan_Kerja &,- 003 & 298 &, 000 & ,000 \\
\hline Kinerja_SDM & ,124 & ,342 & ,285 &, 000 \\
\hline
\end{tabular}

Sumber: Data Primer yang diolah, 2018

Dari informasi di atas, diketahui pengaruh kompetensi terhadap kinerja SDM memiliki pengaruh total $(0,342)$ yang lebih besar dari pengaruh langsung $(0,258)$, artinya kepuasan kerja sebagai variabel yang memiliki peran penting dalam memediasi pengaruh kompetensi terhadap kinerja SDM KPPBC TMP A Semarang.

PEMBAHASAN.

1) Kompetensi berpengaruh positif terhadap kepuasan kerja. Pengujian menunjukkan bahwa pengaruh positif kompetensi terhadap kepuasan kerja 
diperoleh hasil 0,298. Artinya, apabila pimpinan KPPBC Tipe Madya Pabean A Semarang meningkatkan kompetensi berinisiatif, percaya diri, kemampuan beradaptasi, pengaruh dan dampak, dan membangun hubungan kerja yang baik, maka akan meningkatkan kepuasan kerja. Hal ini mengindikasikan bahwa jika pegawai memiliki kompetensi yang diimplementasikan di pekerjaan sehari-hari, pegawaiakan merasa puas dalam bekerja. Hasil ini sesuai dengan pendapat Bogner and Thomas dalam Sari (2013) bahwa kompetensi sebagai keahlian khusus yang dimiliki perusahaan dan pengetahuan yang diarahkan untuk mencapai tingkat kepuasan yang tinggi. Hasil ini juga sejalan dengan hasil penelitian yang dilakukan oleh Dhermawan, dkk (2012) dan Jatnika (2017).

2) Sarana pendukung teknologi informasi tidak berpengaruh positif terhadap kepuasan kerja.Berdasarkan hasil analisis pengujian membuktikan bahwa pengaruh sarana pendukung teknologi informasi terhadap kepuasan kerja diperoleh hasil negatif 0,003 . Hal tersebut menunjukkan bahwa hipotesis ini dalam penelitian tersebut ditolak. Tidak ada pengaruh positif sarana pendukung teknologi informasi terhadap kepuasan kerja. Hasil ini tidak mendukung penelitian Dahlius danIbrahim (2016) dan Ida Rosnidah (2010) yang menyatakan teknologi informasi berpengaruh positif dan signifikan tehadap kepuasan kerja. Bisa jadi sarana pendukung teknologi informasi bukan faktor yang mempengaruhi kepuasan kerja, ada faktor sarana pendukung yang lain.

3) Kompetensi berpengaruh positif terhadap kinerja SDM.Berdasarkan hasil analisis pengujian membuktikan bahwa ada pengaruh positif kompetensi terhadap kinerja SDM dengan diperoleh hasil 0,285. Artinya, apabila pimpinan KPPBC Tipe Madya Pabean A Semarang meningkatkan kompetensi berinisiatif, percaya diri, kemampuan beradaptasi, pengaruh dan dampak, dan membangun hubungan kerja yang baik, maka akan meningkatkan kinerja SDM.Hasil ini sesuaipendapat Robbins (2015) yang menegaskan bahwa seorang pegawai akan memiliki tingkat kinerja tinggi apabila terdapat kesesuaian antara pekerjaan dengan kemampuan. Hasil ini mendukung 
penelitian Hadiyatno(2012) dan Pradiningrum, dkk. (2013) yang menyatakan kompetensi berpengaruh positif dan signifikan tehadap kinerja pegawai.

4) Sarana pendukung teknologi informasi tidak berpengaruhpositif terhadap kinerja SDM.Hasilpengujian membuktikan bahwa pengaruh sarana pendukung teknologi informasi terhadap kinerja SDM diperoleh hasil 0,125, tetapi karena probabilitasnya > 0,05 maka hipotesis ini ditolak. Hal ini tidak sesuai dengan pendapat Widodo (2015) yang menyatakan investasi di bidang teknologi informasi di suatu organisasi dimaksudkan untuk memberi kontribusi terhadap kinerja individual anggota dan organisasi.Hasil ini juga tidak mendukung penelitian Geovannie, dkk. (2013) dan Sukartha, dkk. (2015) yang menyatakan teknologi informasi berpengaruh positif dan signifikan tehadap kinerja individu. Simanjutak (2011) menyatakan bahwa kinerja dapat dipengaruhi oleh sarana pendukung, yaitu hal yang berhubungan dengan lingkungan kerja (keselamatan kerja, kesehatan kerja, sarana produksi, teknologi) dan hal - hal yang berhubungan dengan kesejahteraan pegawai (upah/gaji, jaminan sosial, keamanan kerja). Teknologi merupakan salah satu sarana pendukungyang berhubungan denganlingkungan kerja. Ada kemungkinan kinerja SDM dipengaruhi oleh sarana pendukung lainnya.

5) Kepuasan kerja berpengaruhpositif terhadap kinerja SDM.Hasilpengujian membuktikan bahwa pengaruh kepuasan kerja terhadap kinerja SDM diperoleh hasil 0,297. Hal tersebut menunjukkan bahwa hipotesis H5 dalam penelitian tersebut diterima. Artinya, apabila pimpinan KPPBC Tipe Madya Pabean A Semarang berupaya meningkatkan kepuasan kerja melalui peningkatan kepuasan dengan rekan kerja, kepuasan dengan atasan melalui dukungan maupun kepuasan dengan pekerjaan itu sendiri, maka akan meningkatkan kinerja SDM.Ukuran dari suatu kepuasan kerja sangat didasarkan pada kenyataan yang dialami dan diterima sebagai imbalan dari usaha dan tenaga yang diberikan terhadap organisasi (Robbins, 2006). Hasil ini sesuai dengan pendapat Linjuan (2014) yang menyatakan bahwa kinerja tidak berdiri sendiri tetapi berhubungan dengan kepuasan kerja, dan sesuai pendapat Gorda (2012) bahwa kepuasan kerja adalah faktor pendorong meningkatnya kinerja pegawai.Ini mendukung penelitian Astuti (2010) dan Dhermawan (2012) yang menyatakan terdapat pengaruh positif antara kepuasan kerja terhadap kinerja.. 


\section{PENUTUP}

Hasil dari penelitian inimenghasilkan temuanbahwakepuasan kerja sebagai variabel yang memiliki peran penting dalam memediasi pengaruh kompetensi terhadap kinerja SDM KPPBC TMP A Semarang sehingga menjawab masalah penelitian secarasingkat, bahwa untuk meningkatkan kinerja SDM maka langkah yangperlu dilakukan adalah meningkatkankepuasan kerja pegawai terlebih dahulu melalui peningkatan kompetensi pegawai.Untuk mendapatkan kepuasan kerjadalam mempengaruhi kinerja SDM adalah melihat besarnya kompetensi yang dimiliki pegawai.

Kemudian hasil pengujian juga menunjukkan jika sarana pendukung teknologi informasi tidak berpengaruh positif terhadap kepuasan kerja maupun kinerja SDM.Teknologi merupakan salah satu sarana pendukungyang berhubungan denganlingkungan kerja. Ada kemungkinan kinerja SDM dipengaruhi oleh sarana pendukung lainnya.

Implikasi teoritis dari hasil penelitian inimemberikan dukungan terhadap pendapatBogner and Thomas (1994) bahwa kompetensi sebagai keahlian khusus yang dimiliki perusahaan dan pengetahuan yang diarahkan untuk mencapai tingkat kepuasan yang tinggi, mendukung pendapatRobbins (2015) yang menegaskan bahwa seorang pegawai akan memiliki tingkat kinerja tinggi apabila terdapat kesesuaian antara pekerjaan dengan kemampuan dan pendapatGorda (2012) bahwa kepuasan kerja adalah faktor pendorong meningkatnya kinerja pegawai. Hasil penelitian ini juga dapat digunakansebagai masukan dan sumbangan pemikiran dalammelakukan evaluasi dan program peningkatan kompetensi pegawai, sertakebijakan dalam rangka meningkatkan kepuasan kerjaaparatur sipil negara yang diharapkan dapatmeningkatkan kinerja organisasi sektor publik.

\section{DAFTAR PUSTAKA.}

Antasari, K.C. dan Sukartha, P.D.Y.Y., (2015), Pengaruh Efektivitas Sistem Informasi Akuntansi Dan Penggunaan Teknologi Informasi Pada Kinerja Individual Dengan Kepuasan Kerja Sebagai Variabel Pemoderasi, E-Jurnal Akuntansi, Hal.354-369.

Dhermawan, A.A.N.B., Sudibya, I.G.A. dan Utama, I.W.M., (2012), Pengaruh Motivasi, Lingkungan Kerja, Kompetensi, Dan Kompensasi Terhadap Kepuasan Kerja Dan Kinerja Pegawai, Matrik: Jurnal Manajemen, Strategi Bisnis dan Kewirausahaan, 6(2).

Ferdinand, Augusty, (2014),Metode Penelitian Manajemen, Badan Penerbit Universitas Diponegoro, Semarang.

Fujianti, L., (2012), Pengaruh Profesionalisme Terhadap Komitmen Organisasi dan Kepuasan Kerja serta Dampaknya Terhadap Kinerja Akuntan Pendidik, Prosiding Seminar Nasional Forum Bisnis Dan Keuangan I, Hal.816-829 
Geovannie, H.L., (2016),Pengaruh Pemanfaatan Teknologi Informasi Dan Kesesuaian Tugas-Teknologi Informasi Terhadap Kinerja Individual Instansi Pemerintahan, Jurnal Mahasiswa Perpajakan, 8(1).

Ghozali,Imam, (2014), Konsep Dan AplikasiDengan Program AMOS 22.0, Edisi Keenam, Badan Penerbit Universitas Diponegoro, Semarang.

Hadiyatno, D., (2012),Pengaruh Kompetensi, Kompensasi, Dan KepuasanKerja Terhadap Kinerja Karyawan, Prosiding Seminas, 1(2).

Ibrahim, M. dan Dahlius, A., (2016),Pengaruh Fasilitas Kerja terhadap Kepuasan Kerja Karyawan, Jurnal Online Mahasiswa Bidang Ilmu Sosial dan IlmuPolitik, 3(2).

Moenir, A. S. (2014), Manajemen Pelayanan Umum Di Indonesia, Cetakan Ke Sepuluh, Bum Aksara,Jakarta

Kartika, L. N.danSugiarto, A., (2014), Pengaruh Tingkat KompetensiTerhadap Kinerja Pegawai Administrasi Perkantoran, Jurnal Ekonomi dan Bisnis, 17(1), 73-90.

Mariam, R., (2009), Pengaruh Gaya Kepemimpinan Dan BudayaOrganisasi Terhadap Kinerja Karyawan Melalui Kepuasan Kerja Karyawan Sebagai Variabel Intervening, Tesis, Program Pascasarjana Universitas Diponegoro.

Pariyatin, Y., (2015), Pengaruh Penerapan Teknologi Informasi Terhadap Kualitas Pelayanan Di KampungSampireun Resort \& Spa, Jurnal Algoritma, 12(1).

Pradiningrum, E.R., Larasati, H. dan Santoso, S., (2013),Pengaruh Kompetensi Dan Motivasi Pegawai Terhadap Kinerja Pegawai Sekretariat DPRD kota Semarang, Jurnal kebijakan publik dan manajemen, 2(3), Hal.84-94.

Ridwan, Juniarso dan Sudrajat, A. Sodik (2014), Hukum Administrasi Negara dan Kebijakan PelayananPublik, Penerbit Nuansa Cendikia, Bandung.

Robbins,Stephen P.danTimothy A. Judge, (2015), Perilaku Organisasi Edisi Keenam belas, Salemba Empat, Jakarta.

Rosnidah, I., (2010), Pengaruh Tingkat Pendidikan Auditor, Besarnya KAP dan Penggunaan Teknologi Informasi Terhadap Kepuasan Kerja Auditor Dan Implikasinya Pada Kualitas Audit (Survei pada KAP di Jakarta), Jakarta, Jurnal Akuntansi Universitas Tarumanegara Vol. 14 No, 1.

Sari, Fajar M., (2013), Pengaruh Kompetensi Dan Lingkungan Kerja Terhadap Kepuasan Kerja Dan Kinerja Guru, Jurnal Ilmu Ekonomi \& Manajemen, Vol. 9 No.2. Hal. $137-153$.

Siagian, Sondang P.(2012),Teori Motivasi dan Aplikasinya, PT. Rineka Cipta, Jakarta.

Sudarmanto, (2014), Kinerja dan Pengembangan Kompetensi SDM, Pustaka Belajar, Yogyakarta. 
Veithzal Rivai,(2014), Kepemimpinan dan Perilaku Organisasi,Edisi Keempat, PT. Rajagrafindo Persada, Jakarta.

Waraich, S.B. dan Bhardwaj, G., 2010. Workforce reduction \& HR Competencies: an exploratory study, Indian Journal of Industrial Relations,Hal.100-111.

Wibowo, (2012), Manajemen Kinerja, Edisi Ketiga, PT. Raja Grafindo, Jakarta.

Widodo, (2014), Upaya Peningkatan Kinerja Inovatif Berbasis Pola Kerja Cerdas Dalam Konteks Teknologi Informasi, Jurnal Manajemen Teknologi, Vol. 13, No. 2, Hal. 154-172.

Wijono, S., (2012),Psikologi Industri Dan Organisasi,Edisi Revisi, Kencana Prenada Media Group, Jakarta.

Wirawan, (2012), Evaluasi Kinerja Sumber Daya Manusia: Teori, Aplikasi, Dan Penelitian, Cetakan Ke-1,Salemba Empat, Jakarta. 